\title{
Pharmacological Studies of Root, Fruit and Flower Extracts of Berberis lycium
}

\author{
MANSI GUPTA ${ }^{1}$ and AJAY SINGH ${ }^{\star 2}$ \\ 'Department of Chemistry, Uttaranchal University, Dehradun, Uttarkhand 248007, India, \\ 2 Department of Chemistry, UCALS, Uttaranchal University, Dehradun,Uttarkhand 248007, India. \\ *Corresponding author E-mail: ajay21singh@yahoo.com \\ http://dx.doi.org/10.13005/ojc/340257
}

(Received: January 18, 2018; Accepted: March 02, 2018)

\begin{abstract}
Herbal plants have many bioactive compounds in their different parts which are responsible for biological activities in the body like antimicrobial, antioxidant, anti-inflammatory properties etc. Berberis lycium is one of the most rare herbal plant found in the Garhwal region of Uttarakhand. In the present work different extracts of fruit, roots and flowers of Berberis lycium belonging to the family of berberidaceae were studied and compound were identified as antimicrobial and antioxidant activities were determined. The study revealed the presence of some biologically active components like, 2'-Phenylbenzanilide, Benzamide, N-(1,1'-Biphenyl)-4-yL-, Benzamide, N,N-Diphenyl- etc were detected in flower, fruit and root extract after GC-MS analysis. Methanolic extracts have shown good antimicrobial potential which can be used in medicines after further study in future.
\end{abstract}

Keywords: Antimicrobial activity, Extract, Berberidaceae, antioxidants.

\section{INTRODUCTION}

Plant kingdoms are the rich source of organic compounds, many of which have been used for medicinal purposes. In traditional medicine, there are many natural crude drugs that have the potential to treat many disease and disorders. ${ }^{1-2}$

The Himalaya and its region is rich in terms of herbal plants. Uttarakhand, which includes the major divisions of Kumaun and Garhwal, is a part of Indian Himalayan region and hence is endowed with rich biodiversity. As medicinal plants receive increased scientific and commercial attention, there is increasing pressure on the wild plant populations from which most of the medicinal plants are harvested. Overharvesting of these medicinal plants have led some of the species to become endangered ${ }^{3-4}$. 
Berberis lycium is an evergreen, erect shrub belonging to the family Berberidaceae. The genus Berberis comprises of as many as 500 species. Out of which 77 species are native to India ${ }^{5}$. Berberis lycium grows upto a height of $3 \mathrm{~m}$, with a thick woody shoot and covered with a thin brittle bark. Berberis lycium has bright yellow color flowers, which are hermaphrodite in nature; i.e. both male and female organs are present on the same flower. It is pollinated by insects. The fruits are bluish purple in color on ripening. The fruit is slightly acidic and juicy in nature. The plant possesses wide ecological amplitude and seeds can be grown in sandy, silty or loamy soils 6 .

In this study fruit and flower extracts in addition to root extracts, were taken for detection of bioactive compound and pharmacological activity due to them.

\section{MATERIAL AND METHODS}

\section{Collection of samples}

The roots, fruits and flowers were collected from Garhwal region of Uttarakhand during summer season of May to July and preserved in the advanced chemistry lab of Uttaranchal University, Dehradun.

\section{Extract preparation}

The roots, fruits and flowers were collected separately and were washed thoroughly with running tap water and finally with distilled water. After shade drying for 10-15 days the roots were crushed into powdered form with the help of mortar and pestle. Then it was added to soxhlet assembly for extraction using water, methanol and $n$-hexane. It was heated for about $6 \mathrm{~h}$ at a temperature less than the boiling point of the solvent. The extract was further concentrated by rotary evaporator, residue was stored for further process where as in case of aqueous media same amount of sample was dissolved in water and boiled, filtered and saved for further process ${ }^{7}$.

\section{Collection of bacterial strains}

Total 12 microbial cultures belonging to 8 bacterial species and 4 fungi were used in this study. The identified microorganisms were obtained from Microbiology laboratory, Uttaranchal University, Dehradun.

\section{Antimicrobial activity and antioxidant activity}

The root, fruit and flower extracts of Berberis lycium prepared above were again dissolved in similar methanol, $n$-hexane and water $(100 \mathrm{mg} / \mathrm{ml})$ and sterilized. The antimicrobial activity test was carried out by disk diffusion by using 50il of suspension spread on potato dextrose agar (PDA), Mueller hinton agar (MHA) media respectively. The disks $(6 \mathrm{~mm})$ containing $10 \mu \mathrm{l}$ of extracts $(300 \mu \mathrm{g} /$ disk) with the concentration of $100 \mathrm{mg} / \mathrm{ml}$ were impregnated in the inoculated agar. Negative control was prepared by using similar solvents of plant extracts. The inoculated plates were incubated at $37^{\circ} \mathrm{C}$ for $24 \mathrm{~h}$ in the case of clinical bacteria strains, $72 \mathrm{~h}$ for fungi isolate. First, inhibitory activity was tested in different solvent extracts of root, flower and fruits. Solvent extracts which have shown positive antimicrobial activity were taken for detailed zone of inhibition by disc diffusion method. Antimicrobial activity was assessed by measuring inhibition zones in reference to test organisms and each process was repeated to get more precise results. Antioxidant activity of the selected plant extracts were measured by the Enzymatic Antioxidant and Non- Enzymatic Antioxidants methods. The enzymatic antioxidant properties were determined by superoxide dis-mutase (SOD), and Non Enzymatic Antioxidant property was determined in the form of vitaminC. i.e ascorbic acid and betacarotene bleaching method ${ }^{8-9}$.

\section{Observations}

The results observed are presented in the form of tables are given below. Antimicrobial effect have been measured in terms of zone of inhibition (mm), which is given in Table 1 and antifungal effect have been shown in Table 2 . 
SINGH et al., Orient. J. Chem., Vol. 34(2), 1055-1062 (2018)




Table 3: Enzymatic antioxidant acitivity (SOD)

\begin{tabular}{llc}
\hline $\begin{array}{l}\text { Part } \\
\text { used }\end{array}$ & $\begin{array}{c}\text { Solvent } \\
\text { extract }\end{array}$ & $\begin{array}{c}\text { SOD } \\
\text { ( unit/mg of protein) }\end{array}$ \\
\hline Roots & Aqueous & 18.5 \\
Roots & methanol & 10.2 \\
Roots & n-hexane & 19.7 \\
Fruit & Aqueous & 20.1 \\
Fruit & methanol & 21.0 \\
Fruit & n-hexane & 18.9 \\
Flower & Aqueous & 16.0 \\
Flower & methanol & 15.8 \\
Flower & n-hexane & 15.2 \\
\hline
\end{tabular}

Table 4: Antioxidant activities of extract with DPPH assay

\begin{tabular}{lcc}
\hline $\begin{array}{l}\text { Plant } \\
\text { Part }\end{array}$ & $\begin{array}{c}\text { Solvent } \\
\text { extract }\end{array}$ & $\begin{array}{c}\text { DPPH } \\
\text { Inhibition \% }\end{array}$ \\
\hline Root & Aqueous & 72 \\
Root & Methanol & 62 \\
Root & n-hexane & 78 \\
Fruit & Aqueous & 65 \\
Fruit & Methanol & 55 \\
Fruit & n-hexane & 70 \\
Flower & Aqueous & 56 \\
Flower & Methanol & 48 \\
Flower & n-hexane & 68 \\
\hline
\end{tabular}

Table 5: Estimation of non-enzymatic antioxidant (Vitamin C )

\begin{tabular}{lcc}
\hline Plant Part & Solvent extract & Vitamin C \\
\hline Root & Aqueous & $1.4 \mathrm{mg} / \mathrm{g}$ \\
Root & Methanol & $1.2 \mathrm{mg} / \mathrm{g}$ \\
Root & n-hexane & $1.7 \mathrm{mg} / \mathrm{g}$ \\
Fruit & Aqueous & $2.5 \mathrm{mg} / \mathrm{g}$ \\
Fruit & Methanol & $1.4 \mathrm{mg} / \mathrm{g}$ \\
Fruit & n-hexane & $1.2 \mathrm{mg} / \mathrm{g}$ \\
Flower & Aqueous & $1.9 \mathrm{mg} / \mathrm{g}$ \\
Flower & Methanol & $1.1 \mathrm{mg} / \mathrm{g}$ \\
Flower & n-hexane & $1.2 \mathrm{mg} / \mathrm{g}$ \\
\hline
\end{tabular}






Fig. 1. GC-MS of Root extract(Methanol)

Table 6: Compounds identified in GC-MS analysis ( Root Extract)

\section{S.No Compound name}

Molecular Molecular weight Formula

\begin{tabular}{llll}
\hline 1. & 2'-Phenylbenzanilide & 273 & $\mathrm{C}^{19} \mathrm{H}^{15} \mathrm{ON}$ \\
2. & Benzamide, & 273 & $\mathrm{C}^{19} \mathrm{H}^{15} \mathrm{ON}$ \\
& N-(1,1'-biphenyl)-4-yl- \\
Benzamide, & & \\
N,N-diphenyl- & 273 & $\mathrm{C}^{19} \mathrm{H}^{15} \mathrm{ON}$ \\
& & \\
\hline
\end{tabular}



\section{RESULT AND DISCUSSION}

It is evident that the inhibitory activity was exhibited by the components present in Berberis lycium and not by the solvents used for extraction. From Table 1, it is clear that methanolic and aqueous extracts of flower followed by fruit and then followed by root have shown antimicrobial potential against selected stains. Flower extract is most potent against most of the selected bacterial

, 19-Apr-2017+ 13:58:44 Bcon E-:

Fig. 2. GC-MS of Fruit Extract (Methanolic) 
Table 7: Compounds identified in GC-MS analysis ( Fruit Extract)

\begin{tabular}{clcc}
\hline S.No & Compound name & $\begin{array}{c}\text { Molecular } \\
\text { weight }\end{array}$ & $\begin{array}{c}\text { Molecular } \\
\text { Formula }\end{array}$ \\
\hline 1. & $\begin{array}{l}\text { Napthalene, } \\
\text { 3-Benzyl-1, } \\
\text { 2-Dihydro }\end{array}$ & 220 & $\mathrm{C}^{17} \mathrm{H}^{16}$ \\
\end{tabular}

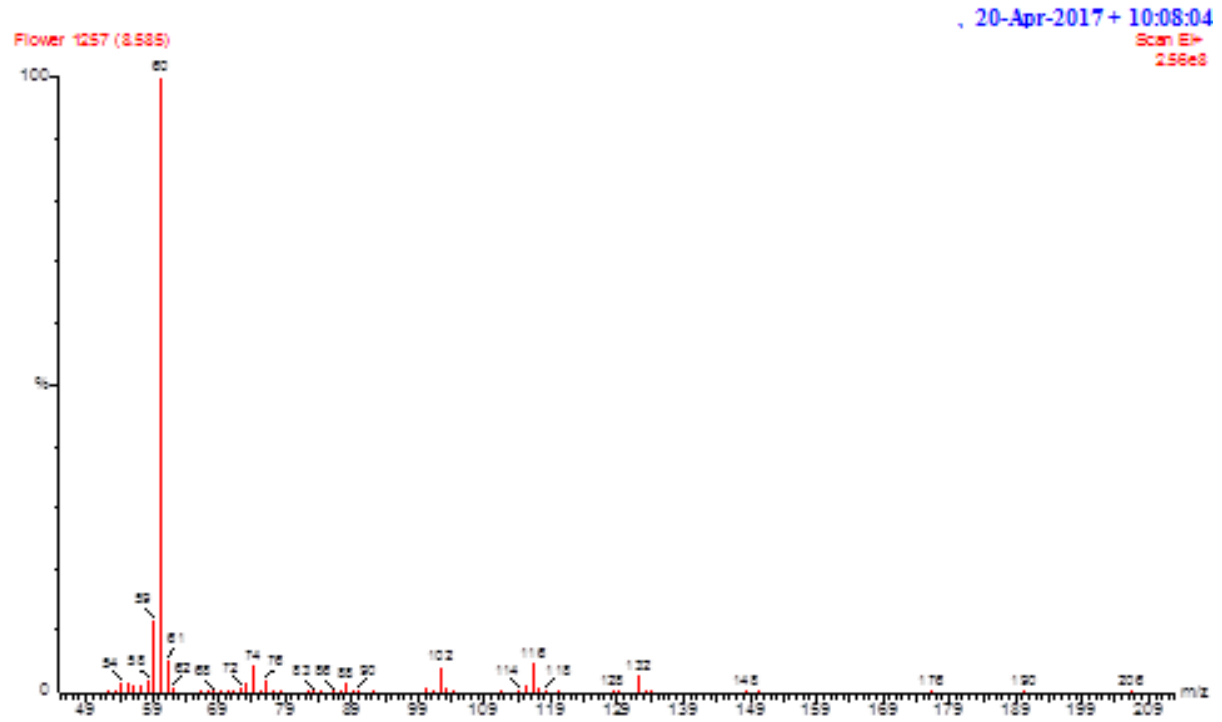

Fig. 3. GC-MS of Flower Extract (Methanolic) stains. Alcoholic extract of flower have shown maximum $28 \mathrm{~mm}$ zone of inhibition against bacteria Enterococcus (Gram positive) followed by Pseudomonas aeruginosa (Gram negative). In n-hexane extract it was found most potent against Pseudomonas aeruginosa and Enterococcus of $18 \mathrm{~mm}$.

Aqueous extract of root have shown sensitivity against salmonella followed by

Table 8: Compounds identified by GC-MS Analysis (Flower extract)

\begin{tabular}{llcc}
\hline S.No & Compound Name & Molecular weight & Molecular Formula \\
\hline 1. & $3(2 \mathrm{H})$-Thiophenone,Dihydro-2-Methyl & 116 & $\mathrm{C}^{5} \mathrm{H}^{8} \mathrm{OS}$ \\
2. & Butane,1-(Ethenylthio)- & 116 & $\mathrm{C}^{6} \mathrm{H}^{12} \mathrm{~S}$ \\
\hline
\end{tabular}

Pseudomonas, similar trend of result was obtained by Ursoon Khan for anti-microbial effect of root extract of Berberis lycium ${ }^{10}$. Methanolic extract have shown maximum anti-microbial effect against salmonella (Gram negative) followed by Acinetobacter baumannii and Klebsiella pneumoniae. Alcoholic extract was not found effective against Staphylococcus aureus and E.coli. ${ }^{8}$ reported that root extract not effective against Staphylococcus aureus, Escherichia coli and Klebsiella. Those results are almost similar for root extract with the finding in this study.

Aqueous fruit extract is effective against most of the bacteria selected and found to be most effective against Pseudomonas aeruginosa (Gram negative) with $16 \mathrm{~mm}$ zone of inhibition followed by $15 \mathrm{~mm}$ against Enterococcus (Gram positive). In this study it was observed that aqueous extract of fruit of Berberis lyclum is more potent than alcoholic fruit extract.

Flower extracts have shown antimicrobial effect against almost all bacterial strains, its flower extract was observed to be most effective against Acinetobacter baumannii $(20 \mathrm{~mm})$ followed by Pseudomonas aeruginosa $(17 \mathrm{~mm})$ and $16 \mathrm{~mm}$ against Enterococcus. Alcoholic extract of flower has shown maximum anti-microbial effect against Enterococcus ( $28 \mathrm{~mm}$ ) followed by Pseudomonas 
aeruginosa which is higher than shown by standard antibiotic(ciprofloxacin). ${ }^{11}$ also studied antibacterial activity of root extract of this plant and results are almost in similar trend ${ }^{11}$. It can also be concluded that methanol is better solvent for antimicrobial activity of root extract similar to findings obtained by $^{7}$. Overall in this study we observed strong antibacterial potential in flower extract followed by fruit and root extract. It was observed that the results of antibiotic properties almost in the similar trend ${ }^{12}$. It was found in their studied that berberine is main compound which is responsible for biological $\operatorname{activity}^{12-13}$.

From Table 2 it is observed that flower extract is most potent extract against all the selected fungal strains while root extract was observed to be least effective. Alcoholic extract (flower) when tested against the fungal strains exhibited maximum inhibitory zone against a.cuboida followed by A.niger and A.fumigatus while Aqueous extract (flower) was observed to be almost ineffective. Fruit extract was observed to be effective against $A$.niger.

In this study investigating the in vitro antimicrobial activity, the results showed that the methanolic extract of flowers and fruit extract (methanolic extract) from Berberis lycium possessed maximum antibacterial activity in comparison to other extract which showed some or no activity, confirming the great potential of bioactive compounds.

Antioxidant activity has shown the presence of some antioxidant like vitamin C. Vitamin $\mathrm{C}$ is found to be highest in aqueous fruit extract 2.5 $\mathrm{mg} / \mathrm{g}$ then followed by aqueous flower extract 1.9 $\mathrm{mg} / \mathrm{g}$ showing the potential for future use. As shown in the Table 5. In Table 3. showed the presence of enzymatic antioxidant was 20.1 in aqueous fruit extract while 21.0 (unit/mg of protein) in methanolic fruit extract. 19.7 was found in $n$-hexane root extract.

Highest percentage of DPPH was found in n-hexane root extract followed by aqueous root extract that was 72 as shown in the Table 4.

Further when GC-MS of root, fruit and flower extract was done in which some bioactive compounds were identified. From Table 6 it was observed that these compounds were identified 2'-Phenylbenzanilide , Benzamide, N-(1,1'-Biphenyl)4-YL-, Benzamide, N,N-Diphenyl. GC-MS analysis of methanolic fruit extract as shown in the Table 7 two compounds were identified 1-(4Methylphenyl)4-Phenylbuta-1,3-diene and Napthalene, 3-benzyl1,2-Dihydro. GC-MS flower methanolic extract showed the presence of 1,3,2-Oxathiaborole, 2-Ethyl-, 3(2H)-Thiophenone,Dihydro-2-Methyl and Butane, 1-(Ethenylthio)- as shown in the Table 8.

\section{CONCLUSION}

This means that some components are present in the root, fruit and flower of Berberis lycium that are responsible for the inhibitory activity of some of the bacterial and fungal strains. In vivo data may be helpful in determining the real potential usefulness of this plant for the treatment of infectious diseases. The medicinal plants have shown to have safety and efficacy in pharmacological activities including as antifungal activity.

The results showed that the flower, fruit and root extracts of Berberis lycium possessed good antimicrobial and antioxidant activity, confirming the great potential of bioactive compounds and are useful for rationalizing the use of this plant in primary health care. In vivo data may be helpful in determining the real potential of flower, fruit and root extracts of this plant.

\section{REFERENCES}

1. Anwar, AK., Ashfaq, M. and Nasveen, MA. (1979): Pharmacognostic studies of selected indigenous plants of Pakistan, (Peshawar, NWFP, and Pakistan: Pakistan Forest Institute). 2. Manik Sharma et al. Multi-therapeutic activity of Berberis lycium royle: A Review International Journal of Advanced Research., 2016, 4(12), 2419-2431.

3. Medicinal Plants at risk: A native Plant conservation campaign report, Emily Roberson. 
4. Mansi Gupta and Ajay Singh. Antimicrobial activity of extract of Berberis lycium. University Journal of phytochemistry and ayurvedic heights., 2016, 1(20), 51-54.

5. Iqbal Ahmad and Arina Z. Beg.Antimicrobial and phytochemical studies on 45 Indian medicinal plants against multi-drug resistant human pathogens. Journal of Ethnopharmacology., 2001, 74, 113-123.

6. Sajjad Ahmed, Muhammad Shuaib, Kashif Ali, Sajjad Ali and Fida Hussain. Evaluation of different parts of Berberis lycium and their biological activities: a review. Pure Appl. Bio., 2017, 6(3), 897-907.

7. G.V Chandra, M Purohit,1980 Medicinal plants of India. ICMR, New Delhi, 377.

8. T. Husain, R.R Rao and A. Garg. Feddes Repertorium., 1998.

9. Sarwat, Zabta Khan Shinwari and Nisar Ahmad.Screening of potential medicinal plants from district sawat specific for controlling women diseases. Pak.J.Bot., 2012, 44(4), 1193-1198.

10. Sharma R , Medicinal Plants of India, an Encylcopedia, Delhi, Daya Publishing House., 2003.

11. Uroosa Khan and Aziz Fatima. In vitro evaluation of antibacterial activity of Berberis lycium against clinical isolates. Journal of biological research and applied sciences., 2016, 7(2).

12. A.H. Irshad, A.H. Pervaiz, Y.B. Abrar, I. Fahelboum, Bahlul Z.S. Awen. Antibacterial activity of Berberis lycium root extract. Trakia Journal of Sciences., 2013, 1, 88-90.

13. Mansi Gupta, Ajay Singh, Harish Chandra Joshi. Berberis lycium multipotential medicinal application: An overview. International Journal of Chemical Studies., 2015, 3(4), 10-13. 